OPEN ACCESS

Edited by:

Guan Zhu,

Texas A\&M University, United States

Reviewed by:

Gong Cheng,

Tsinghua University, China

Albert Mulenga,

Texas A\&M University, United States

*Correspondence:

Xiao-Guang Chen

xgchen2001@hotmail.com

${ }^{t}$ These authors have contributed equally to this work.

Specialty section:

This article was submitted to Infectious Diseases,

a section of the journal

Frontiers in Microbiology

Received: 14 June 2017 Accepted: 13 November 2017 Published: 01 December 2017

Citation:

Liu Z, Zhang Z, Lai Z, Zhou T, Jia Z,

Gu J, Wu K and Chen X-G (2017)

Temperature Increase Enhances Aedes albopictus Competence

to Transmit Dengue Virus.

Front. Microbiol. 8:2337.

doi: 10.3389/fmicb.2017.02337

\section{Temperature Increase Enhances Aedes albopictus Competence to Transmit Dengue Virus}

\author{
Zhuanzhuan Liu', Zhenhong Zhang', Zetian Lai, Tengfei Zhou, Zhirong Jia, Jinbao Gu, \\ Kun Wu and Xiao-Guang Chen*
}

Department of Pathogen Biology, Guangdong Provincial Key Laboratory of Tropical Disease Research, School of Public Health, Southern Medical University, Guangzhou, China

Dengue is a mosquito-borne disease that has been an epidemic in China for many years. Aedes albopictus is the dominant Aedes mosquito species and the main vector of dengue in China. Epidemiologically, dengue mainly occurs in Guangdong Province; it does not occur or rarely occurs in other areas of mainland China. This distribution may be associated with climate, mosquito density, and other factors in different regions; however, the effect of temperature on the vector competence of Ae. albopictus for dengue viruses (DENV) remains unclear. In this study, Ae. albopictus was orally infected with dengue virus 2 (DENV-2) and reared at constant temperatures $(18,23,28$, and $\left.32^{\circ} \mathrm{C}\right)$ and a fluctuating temperature $\left(28-23-18^{\circ} \mathrm{C}\right)$. The infection status of the midguts, ovaries, and salivary glands of each mosquito was detected by polymerase chain reaction (PCR) at $0,5,10$, and 15 days post-infection (dpi). DENV-2 RNA copies from positive tissues were quantified by quantitative real time PCR (qRT-PCR). At $18^{\circ} \mathrm{C}$, DENV-2 proliferated slowly in the midgut of Ae. albopictus, and the virus could not spread to the salivary glands. At 23 and $28^{\circ} \mathrm{C}$, DENV-2 was detected in the ovaries and salivary glands at $10 \mathrm{dpi}$. The rates of infection, dissemination, population transmission, and DENV-2 copies at $28^{\circ} \mathrm{C}$ were higher than those at $23^{\circ} \mathrm{C}$ at any time point. At $32^{\circ} \mathrm{C}$, the extrinsic incubation period (EIP) for DENV-2 in Ae. albopictus was only $5 \mathrm{dpi}$, and the vector competence was the highest among all the temperatures. Compared with $28^{\circ} \mathrm{C}$, at $28-23-18^{\circ} \mathrm{C}$, the positive rate and the amount of DENV-2 in the salivary glands were significantly lower. Therefore, temperature is an important factor affecting the vector competence of Ae. albopictus for DENV-2. Within the suitable temperature range, the replication of DENV-2 in Ae. albopictus accelerated, and the EIP was shorter with a higher temperature. Our results provide a guide for vector control and an experimental basis for differences in the spatial distribution of dengue cases.

Keywords: Aedes albopictus, dengue virus 2, temperature, vector competence, viral titration

\section{INTRODUCTION}

Dengue virus (DENV) is a mosquito-borne flavivirus that can cause a series of diseases, including dengue fever (DF), dengue hemorrhagic fever (DHF), and dengue shock syndrome (DSS) (Guzman and Harris, 2015). It has been estimated that the total number of people infected with DENV is 390 million per year worldwide, of which 96 million showed clinical symptoms and approximately 
290 million presented inapparent infection (Bhatt et al., 2013). In China, dengue frequently occurs in the warm southern regions, including Guangdong, Hainan, Guangxi, and Fujian Provinces, while few dengue cases are present in the northern regions (Chen and Liu, 2015). During the period 1990-2015, a total of 73,551 dengue cases were reported in China, and the largest outbreak, with 47,056 cases, caused six deaths in 2014 (Lai et al., 2015; Sun et al., 2017). The number of dengue cases in Guangdong Province accounted for $96 \%$ of the national cases in 2014 , and $99.8 \%$ of these cases were indigenous (Xiao et al., 2016; Zhao et al., 2016). Spatial distribution showed that the highest number of cases was found in Guangzhou City, the capital of Guangzhou Province; few cases were present in Shenzhen City; and no cases were seen in Meizhou City (Xiao et al., 2016). These differences in distribution were probably due to climatic fluctuation, population density, mosquito density, and other factors (Jing et al., 2017).

Temperature is an important factor influencing the ecological habits, vector competence, and extrinsic incubation period (EIP) of mosquitoes for DENV (Xu et al., 2017). Compared to the average temperatures in previous years, the average temperature in Guangdong Province was $0.1-1.3^{\circ} \mathrm{C}$ higher from July to September in 2014 (Xiao et al., 2016). The maximum average temperature was $30.8^{\circ} \mathrm{C}$, and the minimum average temperature was $22.8^{\circ} \mathrm{C}$ (Xiang et al., 2017). Daily temperatures fluctuated between the highest and lowest temperatures. At high temperatures $\left(\geq 26^{\circ} \mathrm{C}\right)$, transmission of DENV can be observed within 1 week; however, the EIP of DENV is prolonged at low temperatures $\left(\leq 21^{\circ} \mathrm{C}\right)$ (Carrington et al., 2013). When the temperature is below $18^{\circ} \mathrm{C}$, DENV cannot spread (Shen et al., 2015).

Dengue viruses are mainly transmitted by Aedes aegypti and Aedes albopictus (Carneiro and Travassos, 2016). Ae. albopictus is the most important dengue vector in China and is widely distributed in the southern region, especially in Guangdong Province (Luo et al., 2015). Guangdong Province has a subtropical climate; the warm and humid conditions are suitable for year-round Ae. albopictus breeding. Tires, flower pots, bamboo tubes, and other small containers trapping water are fit for the development of larvae (Li et al., 2014). Adults are active and suck blood many times throughout the day. In this study, based on the average temperature in the Guangzhou region, we collected Ae. albopictus mosquitoes from Foshan, Guangdong Province, and used a DENV-2 strain to compare the vector competence of Ae. albopictus for DENV-2 under different temperature conditions.

\section{MATERIALS AND METHODS}

\section{Mosquitoes}

Aedes albopictus mosquitoes used in this study have been collected from Foshan, Guangdong Province, China, since 1981. Colony maintenance was conducted under standard insectary conditions (constant $27 \pm 1{ }^{\circ} \mathrm{C}, 70-80 \%$ relative humidity, and a $16 \mathrm{~h}: 8 \mathrm{~h}$ light-dark photoperiod). Eggs in de-chlorinated water were hatched to larvae. One hundred larvae per liter of water were fed turtle food with $0.1 \mathrm{~g}$ each day for the first 4 days and then $0.2 \mathrm{~g}$ each day until they pupated. Pupae were transferred to cages $(20 \mathrm{~cm} \times 20 \mathrm{~cm} \times 35 \mathrm{~cm})$. After emergence, adults were provided with $10 \%$ glucose solution or defibrinated sheep blood (Solarbio, Beijing, China) for egg production.

\section{Dengue Virus}

Dengue virus 2 (New Guinea C, GenBank: AF038403.1) was provided by the Key Laboratory of Tropical Disease Control of Sun Yat-sen University (Guangzhou, China). C6/36 cells were cultured in RPMI-1640 medium supplemented with $10 \%$ heatinactivated fetal bovine serum (FBS) and maintained at $28^{\circ} \mathrm{C}$. Cells grown in a $75-\mathrm{cm}^{2}$ culture flask were inoculated with DENV-2 at a multiplicity of infection (MOI) of 1. After gentle shaking for $15 \mathrm{~min}$, the culture flask was incubated at $37^{\circ} \mathrm{C}, 5 \%$ $\mathrm{CO}_{2}$ for 2 days until obvious cytopathic effects. The supernatant was harvested after centrifugation at $1,500 \times g$ for $5 \mathrm{~min}$, separated into $0.5-\mathrm{mL}$ aliquots, and frozen at $-80^{\circ} \mathrm{C}$.

\section{Viral Titration in C6/36 Cells}

Dengue virus 2 titer was determined by $50 \%$ tissue culture infective dose $\left(\mathrm{TCID}_{50}\right.$ ) (Richard et al., 2015). Briefly, C6/36 cells were seeded in a 96-well microtiter plate at a density of $10^{5}$ cells per well and cultured at $28^{\circ} \mathrm{C}$ for $24 \mathrm{~h}$. The control solution (RPMI-1640 containing 2\% FBS) and 10-fold viral dilutions $\left(10^{-1}-10^{-11}\right)$ were inoculated into $\mathrm{C} 6 / 36$ cells in eight wells. The microtiter plate was placed at $37^{\circ} \mathrm{C}, 5 \% \mathrm{CO}_{2}$ for $2 \mathrm{~h}$, and then the culture per well was replaced with RPMI1640 supplemented with $2 \%$ FBS. The plate was incubated at $37^{\circ} \mathrm{C}, 5 \% \mathrm{CO}_{2}$ until the cytopathic effect did not continue to increase. Results were calculated according to the Karber method (Ramakrishnan, 2016).

\section{Oral Infection with DENV-2}

Mosquito infection was conducted in a Biological Safety Level 2 lab. Two days before infection, frozen DENV-2 stock was passaged once more through the $\mathrm{C} 6 / 36$ cells. The titer of the fresh virus was $7.375-7.875 \log _{10} \mathrm{TCID}_{50} / \mathrm{mL}$. The DENV-2 supernatant was collected and mixed with defibrinated sheep blood at a ratio of $2: 1$. The blood meal was maintained at $37^{\circ} \mathrm{C}$ for $30 \mathrm{~min}$ and transferred into a Hemotek blood reservoir unit (Discovery Workshops, Lancashire, United Kingdom). Five- to seven-day-old female Ae. albopictus mosquitoes were glucose starved for 12-24 h and allowed to feed on the infectious blood meal for $30 \mathrm{~min}$. After anesthesia with $\mathrm{CO}_{2}$, fully engorged mosquitoes were removed and placed into $250-\mathrm{mL}$ paper cups covered with gauze (10 mosquitoes/cup). Mosquitoes were placed in different HP400GS incubators (Ruihua, Wuhan, China) precisely set at $18,23,28$, and $32^{\circ} \mathrm{C}$. Another group of mosquitoes was placed at the fluctuating temperature $\left(28^{\circ} \mathrm{C}\right.$ for $14 \mathrm{~h}, 23^{\circ} \mathrm{C}$ for $2 \mathrm{~h}$, and $18^{\circ} \mathrm{C}$ for $8 \mathrm{~h}$ ). The control group was set for each temperature. DENV-2 stock solution was replaced with RPMI1640 containing $2 \%$ FBS in the control group, the remaining steps were the same as mosquitoes engorged with the infectious blood meal. All treatments were maintained at $80 \%$ relative humidity and $16 \mathrm{~h}: 8 \mathrm{~h}$ (light:dark) photoperiod, and all mosquitoes were fed $10 \%$ glucose solution. 


\section{Vector Competence of Ae. albopictus for DENV-2}

The midgut, ovaries, and salivary glands of each mosquito from the abovementioned temperatures were dissected and detected at $0,5,10$, and 15 days post-infection (dpi). The sample size collected from each temperature condition was 3-6 mosquitoes at 0 dpi and 10-16 mosquitoes at each additional time point. The experiment was independently repeated three to five times.

The legs and wings of each mosquito were removed and washed three times in PBS. Disposable insect microneedles were used to separate the midgut, ovaries, and salivary glands of each mosquito under an anatomical lens. Tissues were washed three times in PBS droplets and then transferred to $50 \mu \mathrm{L}$ of TRIzol (Ambion, Life Technologies, Carlsbad, CA, United States) in 1.5-mL Eppendorf tubes. Total RNA was extracted according to TRIzol manufacturer's protocol. cDNA was synthesized using a DENV-2-specific primer ( 5 '-TGGTCTTTCCCAGCGTCAAT$3^{\prime}$ ), and the recommendations of the GoScript ${ }^{\mathrm{TM}}$ Reverse Transcription System (Promega, Madison, WI, United States) were followed.

Polymerase chain reaction (PCR) was used to detect DENV-2 in the tissues. A pair of primers was synthesized as described previously (forward primer: 5 '-TCAATATGCTGAAACGCGC GAGAAACCG-3'; reverse primer: 5'-TTGCACCAACAGTC AATGTCTTCAGGTTC-3') (Lanciotti et al., 1992). The target fragment was $511 \mathrm{bp}$, which was located in the partial capsid and membrane protein region. The total volume of the PCR reaction system was $25 \mu \mathrm{L}$, including $12.5 \mu \mathrm{L}$ Maxima Hot Start Green PCR Master Mix (Thermo Fisher Scientific Inc., Waltham, MA, United States), $0.5 \mu \mathrm{L}$ of each primer $(10 \mu \mathrm{M}), 1 \mu \mathrm{L}$ cDNA, and $10.5 \mu \mathrm{L}$ RNase-free water. PCR reaction conditions were the following: $94^{\circ} \mathrm{C}$ for $3 \mathrm{~min}$, followed by 35 cycles of $94^{\circ} \mathrm{C}$ for $30 \mathrm{~s}, 56^{\circ} \mathrm{C}$ for $30 \mathrm{~s}$ and $72^{\circ} \mathrm{C}$ for $1 \mathrm{~min}$, and $72^{\circ} \mathrm{C}$ for $7 \mathrm{~min}$. PCR products were identified by $1 \%$ agarose gel electrophoresis, ligated with pMD18-T (Takara, Dalian, China) and confirmed by sequencing. Comparing to the tissues from the control group, the positive tissues were determined by detecting specific DENV-2 sequence.

The vector competence of Ae. albopictus for DENV-2 transmission was evaluated by infection rate (IR), dissemination rate (DR), and population transmission rate (PTR), as follows (Di Luca et al., 2016):

IR $=$ the number of positive midguts/the total number of midguts

$\mathrm{DR}=$ the number of positive ovaries/the number of positive midguts

PTR $=$ the number of positive salivary glands/the total number of tested mosquitoes.

\section{Quantification of DENV-2 in the Tissues}

The amount of DENV-2 in the positive tissues of mosquitoes was further detected by absolute quantitative real-time PCR (qRT-PCR). The plasmid standard was constructed as previously described (Zhang et al., 2010). In brief, the $3^{\prime}$-UTR region of DENV-2 was amplified by PCR using specific primers (forward primer: 5'-TCCCTTACAAATCGCAGCAAC-3'; reverse primer:
5'-TGGTCTTTCCCAGCGTCAAT- $3^{\prime}$ ). The fragment with 127 bp was cloned into pMD18-T and linearized by EcoRI. The concentration of the plasmid was $26.9 \mathrm{ng} / \mu \mathrm{L}$, which was transformed into a copy number $\left(8.71 \times 10^{9} / \mu \mathrm{L}\right)$.

The qRT-PCR reaction mixture per well contained $10 \mu \mathrm{L}$ SYBR $^{\circledast}$ selected master mix, $1 \mu \mathrm{L}$ of each primer $(10 \mu \mathrm{M})$, $2 \mu \mathrm{L}$ cDNA or the plasmid standard, and $6 \mu \mathrm{L}$ RNase-free water. The reaction was performed in the 7500 Real-Time PCR System as follows: $50^{\circ} \mathrm{C}$ for $2 \mathrm{~min}, 95^{\circ} \mathrm{C}$ for $2 \mathrm{~min}$, followed by 40 cycles of $95^{\circ} \mathrm{C}$ for $15 \mathrm{~s}, 60^{\circ} \mathrm{C}$ for $15 \mathrm{~s}$, and $72^{\circ} \mathrm{C}$ for $1 \mathrm{~min}$. Melting curves were given at $95^{\circ} \mathrm{C}$ for $15 \mathrm{~s}, 60^{\circ} \mathrm{C}$ for $1 \mathrm{~min}, 95^{\circ} \mathrm{C}$ for $30 \mathrm{~s}$, and $60^{\circ} \mathrm{C}$ for $15 \mathrm{~s}$. A standard curve was established by 10 -fold dilutions of the plasmid standard $\left(8.71 \times 10^{2}-8.71 \times 10^{7}\right)$. The result of qRT-PCR was ascertained by using non-template, negative (mosquito infected with C6/36 cells) and positive control (mosquito infected with DENV-2 at $0 \mathrm{dpi}$ ). Its minimum detecting amount is 87.1 copies/reaction of DENV-2. Each sample was conducted in three replicates, and the results were determined by the melting curve and cycle threshold values.

\section{Data Analysis}

All statistical analyses were performed with SPSS 20.0 (IBM, Chicago, IL, United States). Under constant temperature, the vector competence of Ae. albopictus for DENV-2 was analyzed using logistic regression. IR, DR, and PTR were separately compared at different temperatures or different time points. $P$-value was corrected by Bonferroni adjustments. Chi-square (and Fisher's exact) tests were used to determine the difference in vector competence between $28^{\circ} \mathrm{C}$ and the fluctuating temperature $\left(28-23-18^{\circ} \mathrm{C}\right)$. The amounts of DENV2 in the tissues were log-transformed and then analyzed by post hoc Tukey's LSD tests of variance analysis for the constanttemperature groups. Student's $t$-test was used to compare the DENV-2 titer of the tissues between $28^{\circ} \mathrm{C}$ and $\left(28-23-18^{\circ} \mathrm{C}\right)$. $P<0.05$ was considered statistically significant.

\section{RESULTS}

\section{Temperature Affects Vector Competence of Ae. albopictus for DENV-2 Constant Temperatures}

In this study, a total of 602 Ae. albopictus females reared at 18, 23,28 , and $32^{\circ} \mathrm{C}$ were used to measure the rates of infection, dissemination, and transmission of DENV-2. At $0 \mathrm{dpi}$, the IRs of mosquitoes were $100 \%$ at all temperatures, indicating that all mosquitoes ingested the blood meal containing DENV-2 (Figure 1A). After the infectious blood meal was digested, the IRs of Ae. albopictus at 18,23 , and $28^{\circ} \mathrm{C}$ were significantly reduced at 5 dpi compared with 0 dpi $(z=10.329, P=0.001$; $z=4.149, P=0.0042 ; z=4.565, P=0.003)$ and then gradually increased at 10 and $15 \mathrm{dpi}$ (Figure 1A). However, Ae. albopictus maintained an invariably high IR at $32^{\circ} \mathrm{C}$, and no significant difference was present at any time point (Figure 1A). At $5 \mathrm{dpi}$, the IR of Ae. albopictus was obviously lower at $18^{\circ} \mathrm{C}$ than that at 

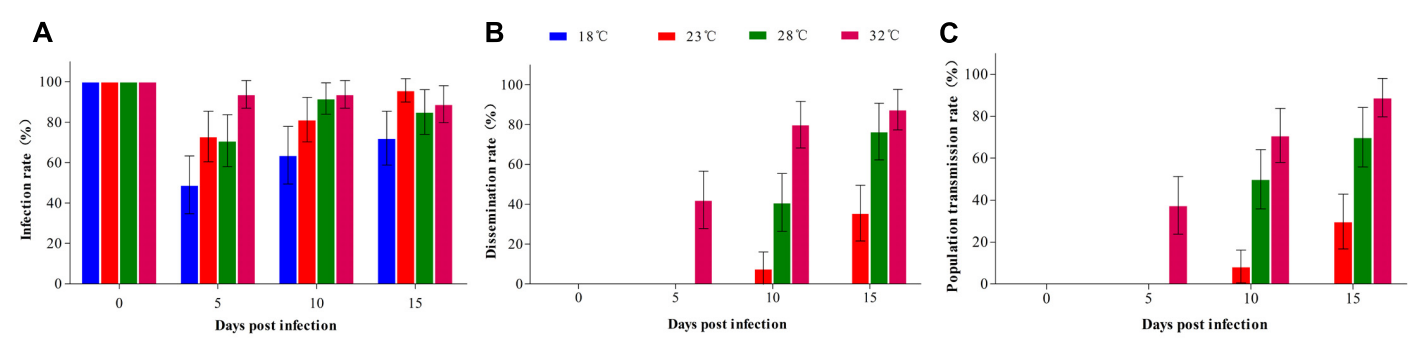

FIGURE 1 | Vector competence of Ae. albopictus orally infected with DENV-2 at different temperatures. Ae. albopictus orally infected with DENV-2 were reared at $18,23,28$, and $32^{\circ} \mathrm{C}$. The midguts, ovaries, and salivary glands of mosquitoes reared at each temperature were dissected at $0,5,10$, and 15 days post-infection and detected by PCR. (A) Infection rate (IR): no. positive midguts/total no. midguts; (B) Dissemination rate (DR): no. positive ovaries/no. positive midguts;

(C) Population transmission rate (PTR): no. positive salivary glands/total no. mosquitoes. Error bars represent 95\% confidence interval (Cl).

the other three temperatures $(z=8.991, P=0.003 ; z=7.538$, $P=0.006 ; z=17.448, P<0.001)$. IRs at 23 and $28^{\circ} \mathrm{C}$ showed no difference; however, they were lower than the IR at $32^{\circ} \mathrm{C}$ $(z=6.048, P=0.014 ; z=6.933, P=0.008)$. At 10 and $15 \mathrm{dpi}$, IRs at 23,28 , and $32^{\circ} \mathrm{C}$ were not significantly different; however, they were higher than the IRs at $18^{\circ} \mathrm{C}(z=15.374,21.725,9.975$, $P<0.01 ; z=20.990,15.110,9.563, P<0.01)$.

Dengue virus 2 was disseminated to the ovaries as early as $5 \mathrm{dpi}$ at $32^{\circ} \mathrm{C}$; however, the DR was low at this point. DRs at 10 and 15 dpi were significantly higher than those at $5 \mathrm{dpi}(z=12.085$, 15.546, $P<0.01$ ), and no difference occurred between 10 and 15 dpi (Figure 1B). At 23 and $28^{\circ} \mathrm{C}, \mathrm{DENV}-2$ detected in the ovaries started $10 \mathrm{dpi}$, and the DR at $15 \mathrm{dpi}$ was higher than that at $10 \mathrm{dpi}(z=7.434, P=0.006 ; z=8.841, P=0.003)$. At $10 \mathrm{dpi}$, the DR arranged in descending order was 32,28 , and $23^{\circ} \mathrm{C}$, and there were significant differences between any two temperatures (Figure 1B). At $15 \mathrm{dpi}$, the DR was still lower at $23^{\circ} \mathrm{C}$ than that at $28^{\circ} \mathrm{C}(z=12.659, P<0.00)$ and $32^{\circ} \mathrm{C}(z=19.429, P<0.001)$; however, no difference appeared between 28 and $32^{\circ} \mathrm{C}(\mathrm{z}=1.402$, $P=0.236)$. No positive ovaries were detected at $18^{\circ} \mathrm{C}$ during the experiment (Figure 1B).

The infection status in the salivary glands was similar to that in the ovaries. Detection of DENV-2 in the salivary glands was $5 \mathrm{dpi}$ at $32^{\circ} \mathrm{C}$ and $10 \mathrm{dpi}$ at 23 and $28^{\circ} \mathrm{C}$, and the PTR increased gradually over time (Figure 1C). At $10 \mathrm{dpi}$, the PTR was lower at $23^{\circ} \mathrm{C}$ than those at 28 and $32^{\circ} \mathrm{C}(z=15.974,29.198, P<0.001)$, and the PTR at $28^{\circ} \mathrm{C}$ was lower than that at $32^{\circ} \mathrm{C}(z=4.097$, $P=0.045)$. Similarly, the PTR at $15 \mathrm{dpi}$ was highest at $32^{\circ} \mathrm{C}$ among all temperatures. At $18^{\circ} \mathrm{C}, \mathrm{DENV}-2$ in the salivary glands was negative at all time points of the experiment (Figure 1C).

\section{Fluctuating Temperature}

We separately compared the IR, DR, and PTR of Ae. albopictus reared under constant $\left(28^{\circ} \mathrm{C}\right)$ and fluctuating temperature $\left(28-23-18^{\circ} \mathrm{C}\right)$ conditions. IRs at 0,5 , and $10 \mathrm{dpi}$ showed no significant differences between 28 and $28-23-18^{\circ} \mathrm{C}$; however, the IR at $28^{\circ} \mathrm{C}$ was higher than that at $28-23-18^{\circ} \mathrm{C}$ at $15 \mathrm{dpi}$ $\left(\chi^{2}=4.398, P=0.048\right)$ (Figure 2A). Whether Ae. albopictus was reared at 28 or $28-23-18^{\circ} \mathrm{C}$, positive ovaries and salivary glands were detected at $10 \mathrm{dpi}$. The DR at 10 and $15 \mathrm{dpi}$ showed no difference between mosquitoes from constant and fluctuating temperature conditions (Figure 2B). At $10 \mathrm{dpi}$, the PTR at $28^{\circ} \mathrm{C}$ was the same as that at $28-23-18^{\circ} \mathrm{C}$. However, the PTR at $28^{\circ} \mathrm{C}$ was significantly higher than that at $28-23-18^{\circ} \mathrm{C}$ at $15 \mathrm{dpi}$ $\left(\chi^{2}=11.965, P=0.001\right)$ (Figure 2C).

\section{Temperature Affects the Amount of DENV-2 in the Tissues of Ae. albopictus Constant Temperatures}

The amounts of DENV-2 in the midguts, ovaries, and salivary glands of $A$ e. albopictus were further detected by qRT-PCR. At 0 dpi, DENV-2 titer showed no significant differences among all temperature groups (Figure $3 \mathrm{~A}$ ). At $18^{\circ} \mathrm{C}, \mathrm{DENV}-2$ copies $\left(\log _{10}\right)$ of the midguts decreased markedly from $0(6.33 \pm 0.77)$ to $5 \mathrm{dpi}(4.17 \pm 0.37)$ and then increased slowly over time. Until $15 \mathrm{dpi}$, the level of DENV-2 was still lower than at $0 \mathrm{dpi}$ $(P<0.05)$ (Figure 3A). Similarly, DENV-2 of the midguts at $23^{\circ} \mathrm{C}$ was lower at $5 \mathrm{dpi}$ than that at $0 \mathrm{dpi}$, followed by a rapid recovery. The amount of DENV-2 at $10 \mathrm{dpi}$ was close to that at $0 \mathrm{dpi}$, and no difference was found between 15 and 10 dpi $(P>0.05)$. At $28^{\circ} \mathrm{C}, \mathrm{DENV}-2$ showed a slow increasing trend in the midguts of Ae. Albopictus mosquitoes. DENV2 copies $\left(\log _{10}\right)$ at 10 and $15 \mathrm{dpi}$ were higher than those at 0 and 5 dpi $(P<0.05)$; however, there was no difference between 0 and 5 dpi or between 10 and 15 dpi $(P>0.05)$. At $32^{\circ} \mathrm{C}, \mathrm{DENV}-2$ copies in the midguts increased rapidly to $8.18 \pm 0.66\left(\log _{10}\right)$ before $5 \mathrm{dpi}$ and then trended toward stability (Figure 3A).

Dengue virus 2 detected in the ovaries was the earliest at $32^{\circ} \mathrm{C}$ (Figure 3B). The viral titration ( $\log _{10}$ copies) was $5.75 \pm 0.83$ at $5 \mathrm{dpi}$, and reached its peak at $10 \mathrm{dpi}(7.34 \pm 0.74)$. There was no significant difference between 10 and $15 \mathrm{dpi}(P>0.05)$. DENV2 in the ovaries at 23 and $28^{\circ} \mathrm{C}$ started from 10 dpi. DENV-2 copies were lower at $23^{\circ} \mathrm{C}$ than those at $28^{\circ} \mathrm{C}$; these values were significantly lower than those at $32^{\circ} \mathrm{C}$ by this time $(P<0.05)$ (Figure 3B). After that, the virus in the ovaries at $28^{\circ} \mathrm{C}$ increased quickly from 10 to $15 \mathrm{dpi}$; however, it remained stable at $23^{\circ} \mathrm{C}$ (Figure 3B). The variation trend of DENV-2 titer in the salivary glands was the same as in the ovaries (Figure 3C). DENV-2 copies $\left(\log _{10}\right)$ in the salivary glands at $32^{\circ} \mathrm{C}$ were higher than those at 23 and $28^{\circ} \mathrm{C}$ at any time point, and they were higher at $28^{\circ} \mathrm{C}$ than those at $23^{\circ} \mathrm{C}$ (Figure $3 \mathrm{C}$ ). DENV-2 was not detected in the ovaries or salivary glands at $18^{\circ} \mathrm{C}$ (Figures 3B,C). 

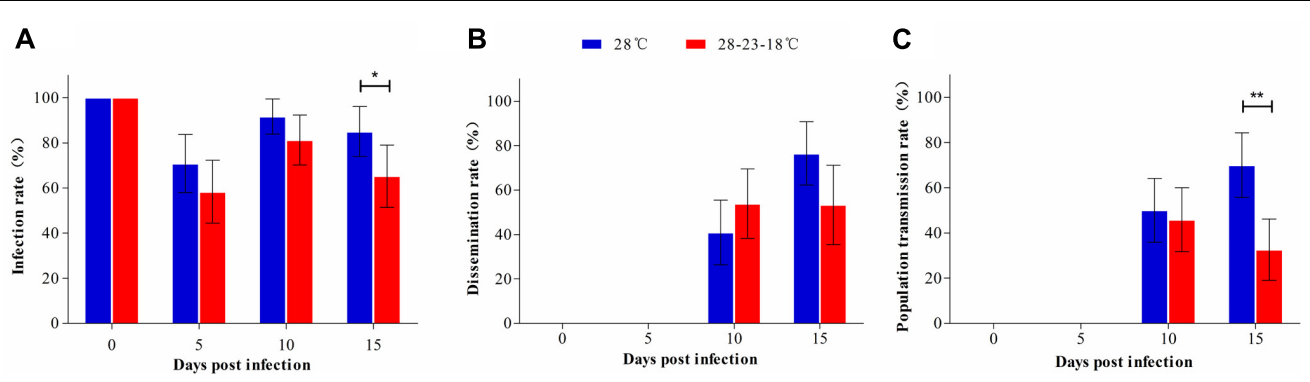

FIGURE 2 | Comparison of vector competence of Ae. albopictus between constant and fluctuating temperatures. The IR, DR, and PTR of Ae. albopictus reared at $28^{\circ} \mathrm{C}$ and $28-23-18^{\circ} \mathrm{C}$ were compared at 0, 5, 10, and 15 dpi. (A) IR; (B) DR; (C) PTR. Error bars represent $95 \%$ Cl. ${ }^{*} P<0.05 ; * * P<0.01$.
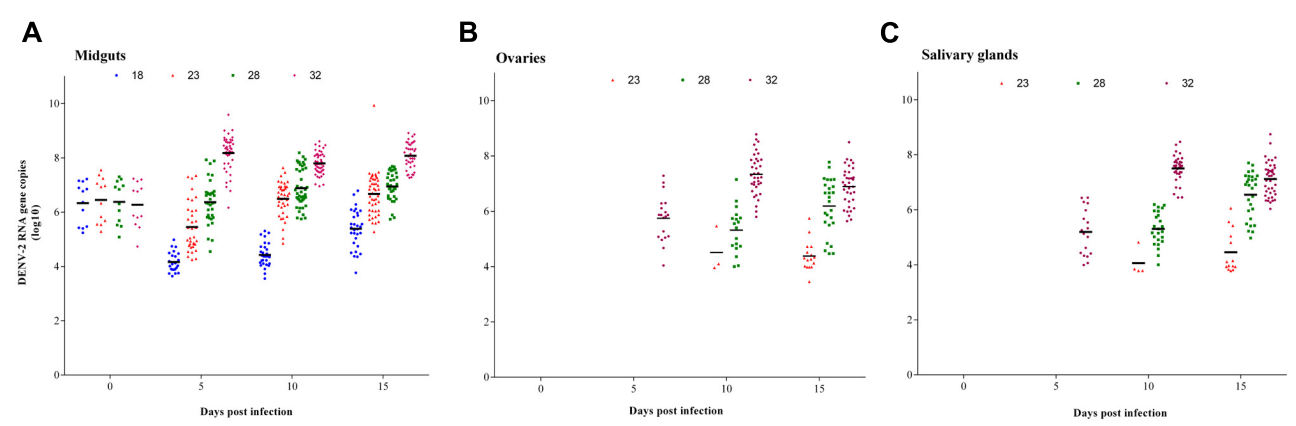

FIGURE 3 | DENV-2 RNA copies in tissues of Ae. albopictus at the constant temperature. The amount of DENV-2 in the positive tissues of Ae. albopictus was further detected by qRT-PCR. (A) Midguts; (B) ovaries; (C) salivary glands. Horizontal black lines show median DENV-2 copies (log 10$)$ at each temperature.
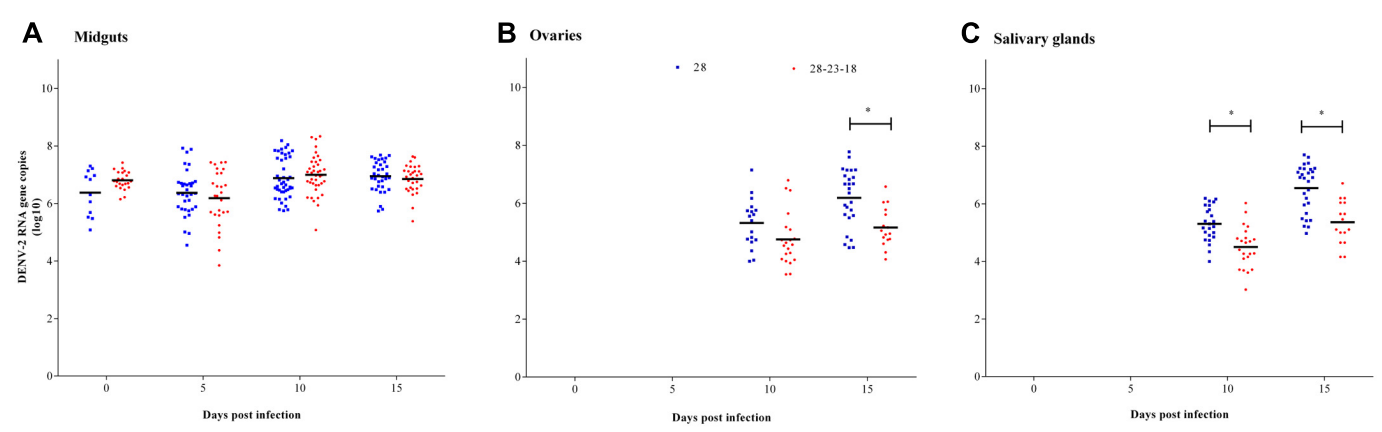

FIGURE 4 | Comparison of DENV-2 RNA copies in tissues of Ae. albopictus between constant and fluctuating temperatures. The amount of DENV-2 in tissues of Ae. albopictus reared at $28^{\circ} \mathrm{C}$ and $28-23-18^{\circ} \mathrm{C}$ was compared at $0,5,10$, and 15 dpi. (A) Midguts; (B) ovaries; (C) salivary glands. Horizontal black lines show median DENV-2 copies $\left(\log _{10}\right)$ at each temperature. ${ }^{*} P<0.05$.

\section{Fluctuating Temperature}

The amounts of DENV-2 in the midguts, ovaries, and salivary glands of Ae. albopictus mosquitoes reared at 28 and $28-23-$ $18^{\circ} \mathrm{C}$ were compared at $0,5,10$, and $15 \mathrm{dpi}$. In the midguts, the DENV-2 copy number showed no difference between constant and fluctuating temperature groups at any time point $(P>0.05)$ (Figure 4A). In the ovaries, the DENV-2 titer at 28 and 28-23$18^{\circ} \mathrm{C}$ showed no significant difference at $10 \mathrm{dpi}$, although it was higher at $28^{\circ} \mathrm{C}$ than that at $28-23-18^{\circ} \mathrm{C}$ at $15 \mathrm{dpi}(P<0.05)$ (Figure 4B). In the salivary glands, DENV-2 copies $\left(\log _{10}\right)$ at $28^{\circ} \mathrm{C}$ were obviously higher than those at $28-23-18^{\circ} \mathrm{C}$ at 10 and $15 \mathrm{dpi}(P<0.05)$ (Figure 4C).

\section{DISCUSSION}

In recent years, the epidemic area of dengue has been expanding with the acceleration of climate warming, trade globalization, and urbanization (Castro et al., 2017). Mosquito control is an effective measure to prevent a dengue outbreak (Pang et al., 2017). Clarifying the vector competence and EIP of Ae. albopictus for the DENV under different temperatures would provide guidance for vector control. Our results showed that DENV-2 was confined to the midguts of Ae. albopictus at $18^{\circ} \mathrm{C}$ and could invade the salivary glands between 23 and $32^{\circ} \mathrm{C}$. Shorter EIPs and higher transmission rates were detected with higher temperatures. 
The lower critical value under which mosquitoes could not spread the virus was reported to be $18^{\circ} \mathrm{C}$ (Shen et al., 2015). In our study, DENV-2 rapidly decreased within 5 days and then slowly increased. DENV-2 could not break through the midgut barrier to spread to the salivary glands during the experimental time. If sufficient time was given, it would be possible to infect the ovaries and the salivary glands. However, Xiao et al. (2014) demonstrated that DENV was still not detected in the salivary glands when the experimental time was extended to 25 dpi.

The EIP at 23 and $28^{\circ} \mathrm{C}$ was consistent (10 dpi). However, the IR, TR, and PTR of Ae. albopictus mosquitoes and the amount of DENV-2 in the tissues were higher at 28 than those at $23^{\circ} \mathrm{C}$ except for $0 \mathrm{dpi}$. The titer of DENV was a key factor affecting mosquito infection. When the $\log _{10}$ plasma viremia level of DENV was between 4 and 10, the susceptibility of Aedes was enhanced with the increase of virus titer, and Ae. aegypti and Ae. albopictus could not be infected when the $\log _{10}$ plasma viremia level was below 4 (Whitehorn et al., 2015). At $23^{\circ} \mathrm{C}$, the viral amount in the ovaries and salivary glands of Ae. albopictus was low (4-4.5 $\log _{10}$ copies/mL). Whether DENV-2 can be transmitted through mosquito bites requires further study.

The EIP of DENV-2 in Ae. albopictus was gradually shortened with rising temperature; therefore, more hosts would be infected by Ae. albopictus bites in the limited reproductive cycle. At $32^{\circ} \mathrm{C}$, DENV-2 could spread to the ovaries and salivary glands of Ae. albopictus by $5 \mathrm{dpi}$. The annual average temperature was higher than $30^{\circ} \mathrm{C}$ from July to October in Guangzhou, and the high density of Ae. albopictus and the short EIP caused an outbreak of dengue during this season. In this study, the upper temperature limit was set at $32^{\circ} \mathrm{C}$ because pre-experimental results showed that the mortality rate of Ae. albopictus was extremely high and the mosquitoes would not survive until the end of the experiment.

In addition, we compared the vector competence and DENV2 titer of Ae. albopictus reared at constant $\left(28^{\circ} \mathrm{C}\right)$ and fluctuating $\left(28-23-18^{\circ} \mathrm{C}\right)$ temperatures. The results showed that, compared with the amount of DENV-2 in the salivary glands at $28^{\circ} \mathrm{C}$, the amount of DENV-2 in the salivary glands at $28-23-18^{\circ} \mathrm{C}$ was significantly decreased. In China, dengue cases occur mainly in warm southern cities, and few cases are present in northern cities.

\section{REFERENCES}

Bhatt, S., Gething, P. W., Brady, O. J., Messina, J. P., Farlow, A. W., Moyes, C. L., et al. (2013). The global distribution and burden of dengue. Nature 496, 504-507. doi: 10.1038/nature12060

Carneiro, L. A., and Travassos, L. H. (2016). Autophagy and viral diseases transmitted by Aedes aegypti and Aedes albopictus. Microbes Infect. 18, 169-771. doi: 10.1016/j.micinf.2015.12.006

Carrington, L. B., Armijos, M. V., Lambrechts, L., and Scott, T. W. (2013). Fluctuations at a low mean temperature accelerate dengue virus transmission by Aedes aegypti. PLOS Negl. Trop. Dis. 7:e2190. doi: 10.1371/journal.pntd. 0002190

Castro, M. C., Wilson, M. E., and Bloom, D. E. (2017). Disease and economic burdens of dengue. Lancet Infect. Dis. 17, e70-e78. doi: 10.1016/S1473-3099(16) 30545-X

Chen, B., and Liu, Q. (2015). Dengue fever in China. Lancet 385, 1621-1622. doi: 10.1016/S0140-6736(15)60793-0
In addition, Guangzhou and Shenzhen are both economically developed, densely populated cities in Guangdong Province; however, the number of cases of dengue was very different in 2014: with 96\% of cases concentrated in Guangzhou. We speculated that diurnal temperature ranges in northern cities and Shenzhen belonging to coastal areas were large. These fluctuations affected the proliferation and spread of the DENV in mosquitoes.

Although we used a single serotype (DENV-2) to detect the vector competence of Ae. albopictus at different temperatures, a previous study showed that the vector competence of Ae. aegypti for different serotypes of DENV (DENV-1 or DENV-2) was similar under similar temperature conditions (Lambrechts et al., 2011). In addition, the survival rate of Ae. albopictus was not considered in this study because it is extremely high in nature, and even a few surviving mosquitoes could transmit DENV to people. To ensure the parallelism of the experiment, adapted mosquitoes in the laboratory were used. It is possible that if first generation lab mosquitoes were to be used, results in this study might be different.

\section{AUTHOR CONTRIBUTIONS}

ZhL and X-GC designed the study. ZhL, ZZ, ZeL, TZ, ZJ, JG, and KW carried out data acquisition and analysis. ZeL wrote the paper. X-GC supervised the study. All authors reviewed the manuscript.

\section{FUNDING}

This study was supported by grants from the National Key Research and Development Program of China (2016YFC1200500, 2017YFC1201004), the National Natural Science Foundation of China (81371845, 81420108024), the Natural Science Foundation of Guangdong Province (2014A030312016), the Guangzhou Synergy Innovation Key Program for Health (201508020263), and the National Institutes of Health, United States (R01AI083202).

Di Luca, M., Severini, F., Toma, L., Boccolini, D., Romi, R., Remoli, M. E., et al. (2016). Experimental studies of susceptibility of Italian Aedes albopictus to Zika virus. Euro. Surveill. 21:30223. doi: 10.2807/1560-7917.ES.2016.21.18.30223

Guzman, M. G., and Harris, E. (2015). Dengue. Lancet 385, 453-465. doi: 10.1016/ S0140-6736(14)60572-9

Jing, Y., Wang, X., Tang, S., and Wu, J. (2017). Data informed analysis of 2014 dengue fever outbreak in Guangzhou: impact of multiple environmental factors and vector control. J. Theor. Biol. 416, 161-179. doi: 10.1016/j.jtbi.2016. 12.014

Lai, S., Huang, Z., Zhou, H., Anders, K. L., Perkins, T. A., Yin, W., et al. (2015). The changing epidemiology of dengue in China, 1990-2014: a descriptive analysis of 25 years of nationwide surveillance data. BMC Med. 13:100. doi: 10.1186/ s12916-015-0336-1

Lambrechts, L., Paaijmans, K. P., Fansiri, T., Carrington, L. B., Kramer, L. D., Thomas, M. B., et al. (2011). Impact of daily temperature fluctuations on dengue virus transmission by Aedes aegypti. Proc. Natl. Acad. Sci. U.S.A. 108, 7460-7465. doi: 10.1073/pnas.1101377108 
Lanciotti, R. S., Calisher, C. H., Gubler, D. J., Chang, G. J., and Vorndam, A. V. (1992). Rapid detection and typing of dengue viruses from clinical samples by using reverse transcriptase-polymerase chain reaction. J. Clin. Microbiol. 30, 545-551.

Li, Y., Kamara, F., Zhou, G., Puthiyakunnon, S., Li, C., Liu, Y., et al. (2014). Urbanization increases Aedes albopictus larval habitats and accelerates mosquito development and survivorship. PLOS Negl. Trop. Dis. 8:e3301. doi: 10.1371/journal.pntd.0003301

Luo, L., Li, X., Xiao, X., Xu, Y., Huang, M., and Yang, Z. (2015). Identification of Aedes albopictus larval index thresholds in the transmission of dengue in Guangzhou, China. J. Vector Ecol. 40, 240-246. doi: 10.1111/jvec. 12160

Pang, T., Mak, T. K., and Gubler, D. J. (2017). Prevention and control of denguethe light at the end of the tunnel. Lancet Infect. Dis. 17, e79-e87. doi: 10.1016/ S1473-3099(16)30471-6

Ramakrishnan, M. A. (2016). Determination of $50 \%$ endpoint titer using a simple formula. World J. Virol. 5, 85-86. doi: 10.5501/wjv. v5.i2.85

Richard, V., Viallon, J., and Cao-Lormeau, V. M. (2015). Use of centrifugal filter devices to concentrate dengue virus in mosquito per os infection experiments. PLOS ONE 10:e0138161. doi: 10.1371/journal.pone.0138161

Shen, J. C., Luo, L., Li, L., Jing, Q. L., Ou, C. Q., Yang, Z. C., et al. (2015). The impacts of mosquito density and meteorological factors on dengue fever epidemics in Guangzhou, China, 2006-2014: a time-series analysis. Biomed. Environ. Sci. 28, 321-329. doi: 10.3967/bes2015.046

Sun, J., Lu, L., Wu, H., Yang, J., Xu, L., Sang, S., et al. (2017). Epidemiological trends of dengue in mainland China, 2005-2015. Int. J. Infect. Dis. 57, 86-91. doi: 10.1016/j.ijid.2017.02.007

Whitehorn, J., Kien, D. T., Nguyen, N. M., Nguyen, H. L., Kyrylos, P. P., Carrington, L. B., et al. (2015). Comparative susceptibility of Aedes albopictus and Aedes aegypti to dengue virus infection after feeding on blood of viremic humans: implications for public health. J. Infect. Dis. 212, 1182-1190. doi: 10.1093/infdis/jiv173

Xiang, J., Hansen, A., Liu, Q., Liu, X., Tong, M. X., Sun, Y., et al. (2017). Association between dengue fever incidence and meteorological factors in Guangzhou,
China, 2005-2014. Environ. Res. 153, 17-26. doi: 10.1016/j.envres.2016. 11.009

Xiao, F. Z., Zhang, Y., Deng, Y. Q., He, S., Xie, H. G., Zhou, X. N., et al. (2014). The effect of temperature on the extrinsic incubation period and infection rate of dengue virus serotype 2 infection in Aedes albopictus. Arch. Virol. 159, 3053-3057. doi: 10.1007/s00705-014-2051-1

Xiao, J. P., He, J. F., Deng, A. P., Lin, H. L., Song, T., Peng, Z. Q., et al. (2016). Characterizing a large outbreak of dengue fever in Guangdong province, China. Infect. Dis. Poverty 5:44. doi: 10.1186/s40249-016-0131-z

Xu, L., Stige, L. C., Chan, K. S., Zhou, J., Yang, J., Sang, S., et al. (2017). Climate variation drives dengue dynamics. Proc. Natl. Acad. Sci. U.S.A. 114, 113-118. doi: $10.1073 /$ pnas. 1618558114

Zhang, M., Zheng, X., Wu, Y., Gan, M., He, A., Li, Z., et al. (2010). Quantitative analysis of replication and tropisms of dengue virus type 2 in Aedes albopictus. Am. J. Trop. Med. Hyg. 83, 700-707. doi: 10.4269/ajtmh.2010.100193

Zhao, H., Zhang, F. C., Zhu, Q., Wang, J., Hong, W. X., Zhao, L. Z., et al. (2016). Epidemiological and virological characterizations of the 2014 dengue outbreak in Guangzhou, China. PLOS ONE 11:e0156548. doi: 10.1371/journal. pone. 0156548

Conflict of Interest Statement: The authors declare that the research was conducted in the absence of any commercial or financial relationships that could be construed as a potential conflict of interest.

The reviewer AM and handling Editor declared their shared affiliation

Copyright (C) 2017 Liu, Zhang, Lai, Zhou, Jia, Gu, Wu and Chen. This is an openaccess article distributed under the terms of the Creative Commons Attribution License (CC BY). The use, distribution or reproduction in other forums is permitted, provided the original author(s) or licensor are credited and that the original publication in this journal is cited, in accordance with accepted academic practice. No use, distribution or reproduction is permitted which does not comply with these terms. 